\title{
An Interview with Dipti Ranjan Pattanaik
}

UMESH KUMAR

Dipti Ranjan Pattanaik (hereafter DRP) holds Professorship at the Department of English, Banaras Hindu University, Varanasi, India. A well-known name in contemporary Odia short story, the Government of Odisha has awarded him the State Sahitya Akademi Award recently. His essays and short stories have appeared in Journal of Commonwealth Literature, MELUS, and Weber Studies among others. He has published four volumes of translation and seven volumes of short stories.

Umesh Kumar (hereafter UK) teaches English studies at the Department of English, Banaras Hindu University, Varanasi, India.

UK: Professor Pattanaik, first thing first how you entered into the field of translation and when?

DRP: (Smiles) you will be surprised to know that I got my first lessons in translation purely because of mercenary reasons. When my father died, the days were still early for me in the college. His demise had left my family and me in great financial distress. To compensate the lack of money, I started translating the radio scripts for All India Radio (AIR). I translated many radio scripts while still at college. Later, these translations also supported my university education, as I had no other source of income. In those days, AIR used to organize a national competition in which the scripts from Indian languages needed to be translated into English accompanied by a synopsis. I remember to have spent sleepless nights translating from Odia to English in the month of December for early January used to be the submission deadline. In those youthful days, I took this task of translation very seriously because it was bread and butter for me. I put my soul in this exercise. In life, most of the tasks undertaken by us are fallouts 
of our innate desires. The desire to satisfy my hunger compelled me to consider translation more than just a job. If I talk about translation per se, I was not aware of various modes of translation at that time. I used to be an instinctive translator engaged in iconic mode of translation. Instinctively, through this model, I would recreate the text in the target language. From early days, I had a flair for rhythm within the language. This helped me to translate poetic pieces from Odia into English. With ease I started to evoke the rhythms of English language in order to assimilate the message of the source (Odia) text in my translation. I must also mention that the only recognition I used to get for these translations was in the form of money. Many of the scripts translated by me went on to win prizes but my importance, as a translator was never mentioned. Later on, through the sophisticated theories of translation I learnt the concept of invisibility of translator! My baptism as a translator was characterized by invisibility sans limelight. However, interviews like this will break that ceiling.

UK: So, something that started as a material need also percolated in your pursuit as an academic? I had a detailed look into your CV and found that along with creative writing, translation in terms of practice, thought and theorization seems to linger as an academic 'obsession. Any specific reasons for such a stance?

DRP: When I entered in the academe as a teacher, for a very long time I was worried by the fact that most of the academic activities undertaken by us (especially) in English Departments were rather mercenary in nature. On the top of it, this approach gets coupled with the psycho-mental slavery imported from the West. For example, the research that was undertaken at that time, the buzzwords circulating among the scholars was the discarded stuff from the western academia. These discarded stuffs reached the academic metropolis of India fifteen years 
after they were abandoned in the West. And to people like us, who were working in the semi-urban, urban colleges of the country these terminologies and academic trends would take another fifteen years to reach. Whenever, I used to visit these metropolis academic centers, I used to feel very strange and disturbed by the kind of language they would use. Let me exemplify this predicament. By the time we got trained in New Criticism, mastered it and thought it to be a religion, I realized that those things had already been discarded thirty years ago by its own proponents. It was not very difficult for me to realize that somehow we will not be able to catch up and be equal either with the metropolitan academic centers of India or with those operating in the West.

It was but natural that I was looking for meaning both in my life and the academic work that I was doing. And then I realized that long ago, when I was a student at Ravenshaw there was a unique Chair Professor. The name of this Chair was Sonpur Chair. The queen of Sonpur had donated money for this particular Chair. Through her intervention, she ensured that this Chair Professorship is reserved for an English Professor. Similarly, she instituted a Chair in Odia language at Calcutta University at the same time. For me, this was lesser a work of charity and more a matter of symbolic significance. In pre-independent India Calcutta was the metropolis of India. Perhaps the queen had sincere insight into a process through which the local can be connected with the global and viceversa. She wanted that Odia episteme should be showcased in the capital (Calcutta), in the centre and the margin (Odia) should be irrigated with English (the 'global' knowledge).

And from that day, I also realized that I should also contribute in this process of connecting the local with the global. Subjectively also, I was in a privileged position. I had studied English seriously to earn my bread and was deeply rooted in 
Odia language as most of us are with our own language and culture. Having almost equal competence in both the languages pumped my resolve. With such a stance, I could bring the global academic capital in Odia and at the same time showcase whatever was worth knowing in Odia episteme to the global. I could actually work as a bridge between these (two) different ontologies. Translation seemed to me the only method through which I could serve these purposes. I realized that this is a more meaningful work in terms of my ability, my expertise, and my political necessity rather than looking for some theoretical role, paradigms and the pursuit of making myself conversant with things looking 'alien' to me at that point of time. However, in the later years because of the arrival of the computer and Internet, knowledge started to reach us much faster. I could have made efforts to keep myself abreast with what was going on in the Western academia but I made no serious efforts in that direction. By that time it became clearer to me that it is futile to propagate others' agenda. Rather, I should make an attempt to remain to my social reality, my people and my language. What I started to do is to translate the influential ideas having high currency in the Western thought into Odia language. At the same time, I started to write on/about Odia episteme in English.

UK: Professor Pattanaik, it compels me to ask a related question at this juncture: How the Odia episteme has historically responded to the idea and practice of translation?

DRP: An important trope of knowledge production, which I think is peculiar to Odia episteme, is its diverse translational practices. I shall exemplify this for you. In Odisha, after the spell of missionary translations during the colonial period, we have almost made a religion out of the iconic translations. We, from then onwards, began to think that the norm for any translation is to be extremely faithful to the source text. 
Conversely, I must mention here that ( $t$ )his norm is not only applicable to Odia episteme alone but percolated to all Indian languages. It became a universal practice, so to speak.

However, such 'faithfulness' wasn't the norm in ancient and especially, medieval Odisha. Translations were done even during these periods. Speaking historically, the first indigenous Odia Empire was established by Kapilendra Deva in the early fifteenth century. I realized that whenever there is an empire building activity, the process of epic writing takes place simultaneously. The same happened in Odia language when Sarala Das wrote its first major epic. And it was a translation of Vyasa's Mahabharata. He not only translated Mahabharata but also translated Bichitra Ramayana and Chandi Purana among others. Further, according to me the choice of these texts was not innocent but informed by Sarala Das' own ideology. Das was a shakta and therefore, he found in Bichitra Ramayana a very liberatory agenda for women. Similarly, Chandi Purana is also a text about powerful women. In Mahabharata also, the potent treatment that he gives to its women characters is again influenced by his shakta worship culture. In fact, while translating Vyasa's Mahabharata into Odia he has made several additions, deletions and mutilation of the text. Let us cite an example to understand this.

In the time of Sarala Das, only Pauranik texts were getting translated and not the 'knowledge' texts. As a result, he refrains from translating the Bhagwat Gita in Odia Mahabharata though it is contained in Vyasa's original work because the Bhagwat Gita was supposed to be a knowledge text. But within the Bhagwat Gita there is a concept called Bishvaroopadarshna. The concept itself is so powerful and dramatic that Sarala Das could not afford to drop it in his version of the Mahabharata. To accommodate it, he introduced a new theme nabagunjara in which Krishna was 
able to show his Bishwaroopa without going into the abstract and philosophical theorization that happens in the Bhagwat Gita. Now, these were the kind of moves, which I think we need to bring to the mainstream of translation theory in the contemporary times.

UK: Just to push you a little bit further is there a relationship between these diverse translational practices and structures of power?

DRP: You are right. In fact, this relationship was inseparable and thrived on each other. Sarala Das himself was a foot soldier in Kapilendra's army. Since Kapilendra had won a huge territory, which went beyond the Odia speaking people to Marathi and Telugu speaking geographies there are more than five translations of Sarala's Mahabharata in Telugu language! Balarama Das repeated a similar model and a new kind of translational practice that was later introduced by Atibadi Jagannatha Das, had its seeds in path undertaken by Sarala. This shows us how structures of power inevitably impact the ongoing translational practices in any given time. And I firmly believe that these varieties and diverse moves of translational practices should not only be shared among our Indian languages but also with the larger world. At the risk of being polemical, I shall argue that such a transaction would show us the channels of alternative modernity (if one thinks that modernity is THE important signpost for circulation of knowledge). It, then, will also puncture a popular myth that modernity was primarily mediated by the western presence both in south Asia and elsewhere.

UK: Then, with your notion of alternative modernity are you suggesting a careful historicization of translational practices?

DRP: Exactly. In fact this is what I have been trying to do in my own work quite religiously. While trying to engage in actual practical translation one should also be sensitive 
towards historicizing the elements that informed the diverse translation practices at a given time in history. When we attempt to negotiate the translation moves undertaken by writers like Sarala Das, Balarama Das and Atibadi Jagannatha Das etc. it is not hard to infer that they constitute "new knowledge' for our field (of translation). For me this new knowledge is also the base for an alternative modernity. If modernity means circulation of knowledge, among many other things how can one ignore the fact that in medieval Odisha more than one hundred and sixty five texts were translated either from Sanskrit to Odia or from Odia to other Indian languages.

UK: Are you, then, also suggesting that historicizing translation practices from the past will help us construct an alternative history of the region itself?

DRP: Yes, but unfortunately not much institutional work has been done in this area though some scholars have been pursuing it quite diligently in their own way. You must be aware that once Sahitya Akademi had this project in mind to come up with the history of translation in major Indian languages. I don't know what happened to that project. Recently, National Translation Mission also came out with a book on a similar subject. We need more of such initiatives. I also feel that there is a great dearth of committed scholars to pursue these types of studies.

Another serious problem that has crept in our academia is the scarcity of bilingual skills. Today, most of the teachers/scholars are trained in such a way that they are extremely competent in one language and not much in the second. This was not the case earlier. In my growing years, I witnessed friends and seniors being equally at ease in English and also in their own mother tongues. We have to 'blame' our contemporary needs for this linguistic extinction. People in the 
past learnt languages with equal proficiency because it was their need. We learn languages because of our need. Today, the kind of social engagements that we make, we can live 'meaningfully' with one language only. But I still believe that for the sake of creating meaningful intellectual capital we need more and more scholars who are conversant in one global language and at the same time deeply rooted in the culture and literature of their own language. Unfortunately, the tribe of such scholars is shrinking day by day.

UK: The way I see it, your analogy of the global and the local seems to put English Departments of our country in a very privileged position?

DRP: Absolutely! But it is again unfortunate that our English Departments have not realized their true mandate. We have been obsessed with the models imported from the western academia and looking for approval from the expatriate scholars belonging to the subcontinent. As an aside, let us take a quick example: most of the scholarly enterprises in India are informed by West can be understood by the example of what happened to the fate of comparative literature departments in our country. May be twenty years ago, the western academy realized that comparative literatures departments are no longer useful to them and they discarded them. Indian academy followed the suit almost immediately. G.N. Devy has written powerfully on this episode of blindfolded imitations and its repercussions for our society. Similarly, how many English teachers are writing and researching in their own languages? Or how many of them are trying to bring the best of regional literature in English? A quick scrutiny of the profiles of English Departments in India will fetch you an answer. In Indian context, English could be our instrument to showcase to the world the best of our regional literatures. Sadly, we have done so little on this front. 
UK: But these transactions are also missing in a major way among Indian languages as well?

DRP: This is a crucial question. One line of thinking on this argues that the proliferation of English language is responsible for the non-communication among Indian languages. However, I would argue for a different turn here. The association of state power with the promotion of a particular language has always been our linguistic reality. And languages promoted so will attempt to spell a hegemonic hold over the other languages. In such a scenario, bhasha languages may themselves become threat to other bhasha languages. The cases of Hindi and Bengali can be cited as examples. After independence, supported by state power, Hindi is promoted to take the role of monologic/monolingual hegemonic role as the language of India. This is the reason that India's southern states have always supported English for they have a fear that otherwise Hindi would come to cannibalize' their languages. Same thing had happened in the case of Bengali. It attempted to cannibalize the eastern languages such as Odia and Assamese and 'indologists' like Raja Rajendralal Mitra played a huge role in it. Because of Bengal's proximity to colonial power and an early access to print technology, it had taken lead in spreading literacy, book production and holistic' knowledge production primarily by engaging with the European models. This early access to knowledge made it easier for Bengalis to channelize and rally available economic opportunities. Thus, Bengali, one of the first languages to translate European renaissance into Indian renaissance began to belittle and marginalize other linguistic groups definitely those who were in its proximity. I have argued elsewhere that the Bengali sub-national hegemony became so invasive that it compelled Odia elite to get united and resist it in a protracted identity struggle. Fakirmohan Senapati was the face of that struggle. 
Instances like these make me assume that the 'subaltern' languages in order to protect themselves, from the hegemonic spell of 'power' languages, had to invariably resort to the idea of rigid linguistic nationalism. And this rigid nationalism blocked the free porous exchange that was happening among bhashas languages earlier.

UK: Prof. Pattanaik, before we close our discussion, it would be interesting to know how translation has impacted you. Usually in translation studies, we seem to be carried away with the idea of translator impacting/ manipulating the text. It can very well be the other way round?

DRP: Your question reminds me my negotiation with Dostoevsky's Notes from Underground as a translator. The translation made me shameless and daring as an author. The epic self-abomination and self-hatred displayed by the protagonist in the Notes from Underground personally liberated me from my own shame and discomfitures. That experience changed the very fabric of my thinking about myself. So I cannot agree more. Translation also affects the translators. At times, in a big way!

UK: Thank you Prof. Pattanaik!

DRP: Smiles!

$$
\text { *** }
$$

\section{Cite this Work:}

Kumar, Umesh. 2020. An Interview with Dipti Ranjan Pattanaik. Translation Today, Vol. 14(2). 201-210. DOI:10.46623/tt/2020.14.2.in3 